\title{
Micromonospora RNA polymerase activity changes during stationary phase
}

\author{
LUNG-SHEN Lin† and David M. RothSTEIN*
}

Department of Microbial Genetics, Lederle Laboratories, Pearl River, NY 10965, USA

(Received 30 March 1992; revised 8 May 1992; accepted 26 May 1992)

\begin{abstract}
RNA polymerase was isolated from Micromonospora echinospora and from Streptomyces lividans. In vitro transcription of a DNA fragment containing multiple tandem promoters from Micromonospora followed the pattern of expression observed previously for in vivo studies. RNA polymerase was prepared from cultures of Micromonospora that were harvested during the growing phase and during the stationary phase. Promoters that were utilized in Micromonospora only during the stationary phase were utilized in vitro only when RNA polymerase was purified from a stationary-phase culture, and not when RNA polymerase was purified from growing cells.
\end{abstract}

\section{Introduction}

Micromonospora echinospora (NRRL 15839) is an actinomycete which grows as multicellular mycelia and is capable of forming spores after the growing phase (Maiese et al., 1989). This micro-organism has generated a great deal of interest, due to its production of the calicheamicins (Lee et al., 1989), a novel family of antitumour antibiotics that cause site-specific doublestranded cleavage of DNA (Zein et al., 1988). Because calicheamicin production is temporally regulated, not being made until stationary phase (Baum et al., 1988), we have been particularly interested in promoters of this species that are turned on at this time of the life cycle.

Multiple tandem promoters within a $0.4 \mathrm{~kb}$ DNA fragment from Micromonospora echinospora have previously been defined. An investigation in which RNA was isolated at different times of the life cycle revealed that three tandem promoters, called P1a, P1b and P1c, were utilized only during stationary phase, while another tandem promoter located downstream, called $\mathrm{P} 2$, was utilized during both the growing and stationary phases (Baum et al., 1988). A transformation system has been described for Micromonospora echinospora, but problems with plasmid maintenance and/or replication have subsequently proved difficult obstacles to conducting genetic studies in that organism (Love \& Rothstein, 1992). Subsequent experiments have relied on the well-

* Author for correspondence. Tel. (914) 732 3063; fax (914) 7355711.

† Present address: Molecular Biology Division, Development Center for Biotechnology, 81 Chang Hsing St., Taipei, Taiwan, ROC. developed tools of $S$. lividans for genetic and biochemical studies, hoping that this related actinomycete would recognize the promoters from Micromonospora. In fact, all of the Micromonospora promoters on the $0.4 \mathrm{~kb}$ fragment (P1a, P1b, P1c, and P2) were utilized in vivo by Streptomyces lividans transformants carrying the $0.4 \mathrm{~kb}$ fragment on a plasmid. One additional promoter, Ptk, was utilized by $S$. lividans transformants but not by the native host (Baum et al., 1988, 1989).

There was a close correspondence between the in vivo results, and in vitro experiments with RNA polymerase isolated from $S$. lividans or $S$. coelicolor, in which runoff transcripts were primed with dinucleotides in order to precisely determine the in vitro start sites (Baum et al., 1989). Both the in vivo and in vitro experiments indicated that the three P1 promoters have unusual structural features. They are very closely spaced, in that Pla, P1b and $P 1 c$ are each separated by $15 \mathrm{bp}$, and therefore their recognition sequences probably overlap. A very unusual aspect is the apparent lack of upstream sequence requirements for the $\mathrm{P} 1 \mathrm{a}$ and $\mathrm{P} 1 \mathrm{~b}$ promoters; substituting DNA just 5 bp upstream of P1a and 20 bp upstream of P1b did not drastically alter the utilization of these promoters in $S$. lividans transformants, whereas the same substitutions had a more marked effect on promoter P1c, whose start site is $35 \mathrm{bp}$ from the substitution (Baum $e t$ al., 1989).

The one disappointment in the Streptomyces experiments was the inability to study the turn-on of expression of the $\mathrm{P} 1$ promoters during stationary phase. Unlike Micromonospora, S. lividans did not exhibit strong temporal regulation of the $\mathrm{P} 1$ promoters, even when the 
P1 promoters were carried on a low copy plasmid (Baum et al., 1988). It was therefore necessary to conduct experiments using the endogenous host to elucidate the mechanism of the temporal regulation of these promoters. In the current study the purification of RNA polymerase from growing and stationary Micromonospora cultures is described, and the in vitro RNA polymerase activity as a function of growth phase is examined.

\section{Methods}

Strains and plasmids. Micromonospora echinospora strain DR46, blocked in the production of calicheamicin (Rothstein \& Love, 1991), and Streptomyces lividans strain TK54 (Hopwood et al., 1985) were used. Plasmid pECl4 (Baum et al., 1988), containing the $0.4 \mathrm{~kb}$ fragment from Micromonospora within a Streptomyces-Escherichia coli shuttle vector, was the source of templates for the in vitro runoff transcription assays.

Purification of RNA polymerase from Micromonospora and Streptomyces. Cells were diluted 1/100 into YEME broth (Hopwood $e t$ al., 1985) for Streptomyces and GER broth (Baum et al., 1988) for Micromonospora, and growth at $30^{\circ} \mathrm{C}$ was monitored by measuring packed cell volume. Cells were harvested during the growing phase (approximately $20 \mathrm{~h}$ incubation) and during stationary phase (45-48 h incubation). RNA polymerase was isolated by Polymin P precipitation, ammonium sulphate precipitation, Sepharose 4B column chromatography, and DNA cellulose chromatography as described by Buttner \& Brown (1985), with the following modifications. Streptomyces cells were disrupted by treating with lysozyme and sonication (MSE sonicator, 18 micron, 80 pulses of $12 \mathrm{~s}$ each on ice) as described by Buttner \& Brown (1985). For Micromonospora cells, lysozyme treatment was not necessary, and cells were disrupted by sonication. Before DNA cellulose chromatography and after the Sepharose 4B column, RNA polymerase fractions were desalted using Amicon Centriprep 30 units ( 3 spins at $15000 \mathrm{~g}$ for $30 \mathrm{~min}$ at $4{ }^{\circ} \mathrm{C}$ ). This method is easier and considerably faster than dialysis.

Protein gels. SDS-PAGE was conducted by the method of Laemmli (1970).

Transcription studies. In vitro runoff experiments were performed as described by Buttner et al. (1987). Activity was determined using calf thymus DNA (Buttner et al., 1987), and 0.1 units were added to each reaction tube. Each runoff assay was repeated at least three times, and representative experiments are shown in Figs 2 and 3. Templates containing the $0.4 \mathrm{~kb}$ region from Micromonospora were obtained by digesting plasmid pEC14 as described in Fig. 2(a).

\section{Results and Discussion}

\section{Isolation of Micromonospora and Streptomyces RNA polymerase}

To study the temporal regulation of Micromonospora promoters, it was necessary to study Micromonospora echinospora, rather than $S$. lividans transformants carrying Micromonospora DNA, which do not exhibit strong temporal regulation of expression of the P1 promoters (Baum et al., 1988). We therefore adapted the methods

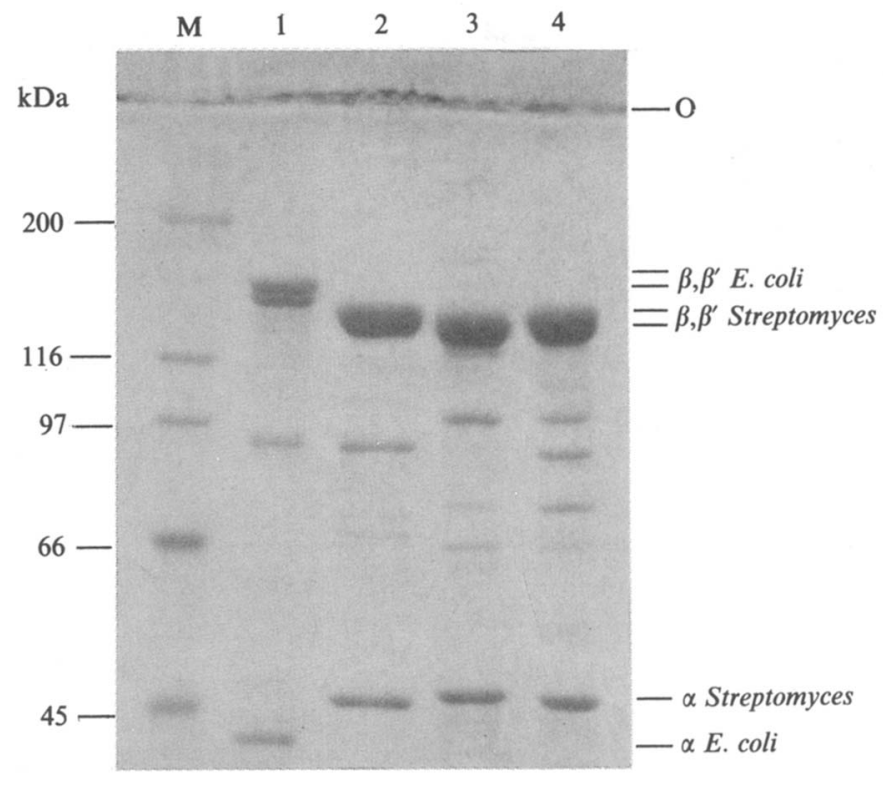

Fig. 1. SDS-PAGE of RNA polymerase preparations from Streptomyces and Micromonospora. Cells of Micromonospora or Streptomyces were harvested during the growing phase or the stationary phase. RNA polymerase was isolated as described, subjected to gel electrophoresis $[7.5 \%(\mathrm{w} / \mathrm{v})$ acrylamide, $0.2 \%$ bis], and visualized by staining with Coomassie Blue R-250. Lanes: M, molecular mass markers (Bio-Rad); 1, $10 \mu \mathrm{g}$ RNA polymerase from E. coli (Boehringer-Mannheim); 2, $20 \mu \mathrm{g}$ RNA polymerase from Streptomyces stationary-phase cells; 3 , $20 \mu \mathrm{g}$ RNA polymerase from Micromonospora stationary-phase cells; 4 , $20 \mu \mathrm{g}$ RNA polymerase from Micromonospora growing cells. The origin of the gel samples is indicated by $O$. Molecular mass markers are labelled to the left, and the $\alpha, \beta$, and $\beta^{\prime}$ subunits of $E$. coli and Streptomyces RNA polymerase are labelled to the right.

previously used to purify RNA polymerase from Streptomyces to isolate RNA polymerase from Micromonospora. We found in particular that lysing by sonication without lysozyme was a more effective way to solubilize RNA polymerase from Micromonospora mycelia.

\section{Composition of Micromonospora RNA polymerase}

The RNA polymerase preparations were subjected to gel electrophoresis (Fig. 1). The $\beta, \beta^{\prime}$, and $\alpha$ subunits of Micromonospora enzyme, whether from stationary cells (lane 3) or growing cells (lane 4), were similar in size to the Streptomyces subunits (lane 2), rather than those of E. coli RNA polymerase (lane 1). This is consistent with the close phylogenetic relationship of Streptomyces and Micromonospora.

\section{Comparison of RNA polymerase activities isolated from Streptomyces and Micromonospora}

Previous in vitro runoff experiments with Streptomyces RNA polymerase and Templates $\mathrm{A}$ and $\mathrm{B}$, containing 
(a) Template A

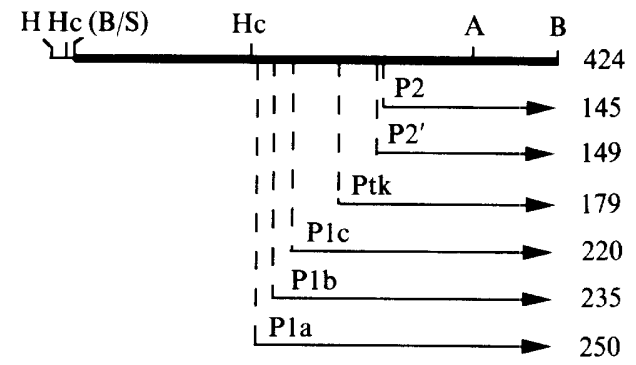

Template B

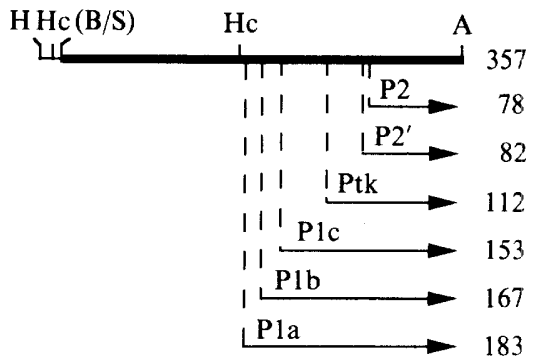

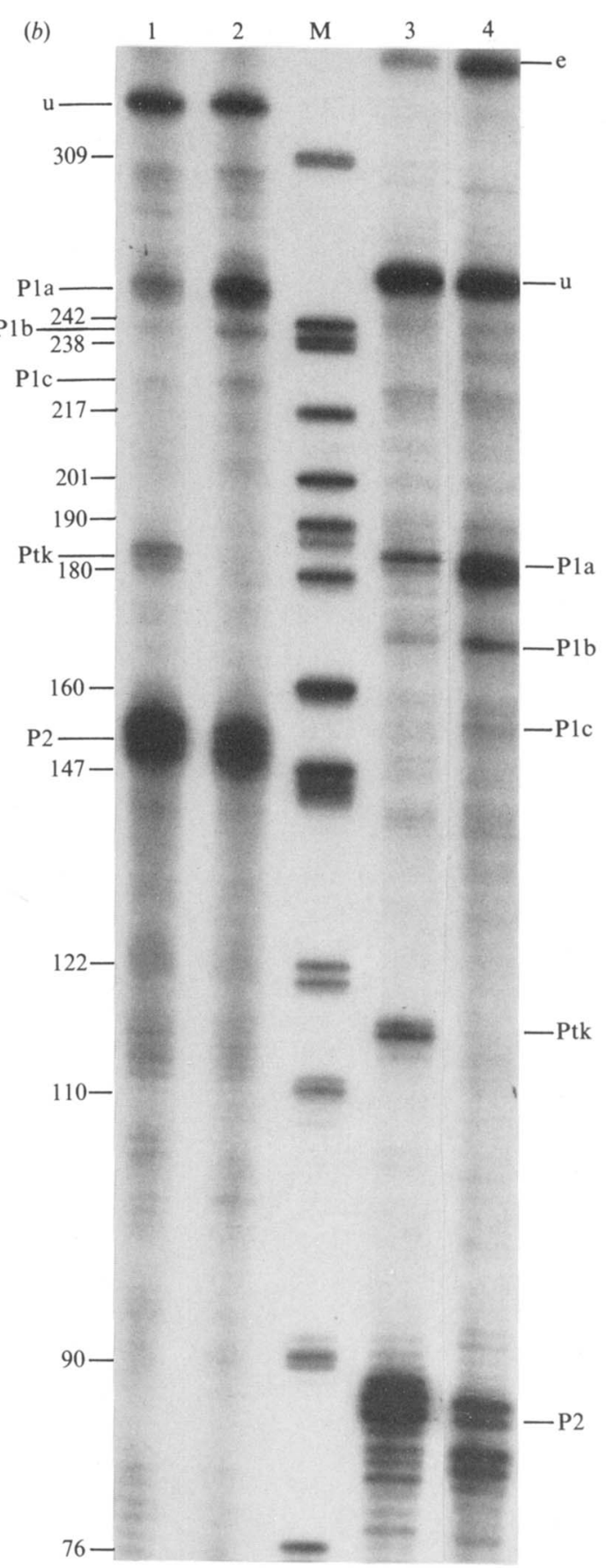

Fig. 2. In vitro runoff transcription of Streptomyces and Micromonospora RNA polymerases, using Micromonospora DNA as template. (a) Templates for in vitro transcription experiments were derived by digesting plasmid pEC14 with HindIII and $\mathrm{BamHI}$ restriction enzymes (Template A) or by digesting plasmid pEC14 with HindIII and AvaI enzymes (Template B). The thick lines indicate Micromonospora DNA from the $0.4 \mathrm{~kb}$ fragment containing the promoters P1a, P1b, P1c, Ptk and P2. The transcription products initiating from these promoters are indicated by arrows. The number next to each arrow is the size of the transcript in nucleotides, determined previously (Baum et al., 1989). The size of each template is listed next to the thick line. Restriction sites are AvaI (A), BamH1 (B), HindIII (H), HincII (Hc), and Sau3Al (S). (b) In vitro runoff transcription products. DNA templates derived from the $0.4 \mathrm{~kb}$ fragment of Micromonospora were incubated with the RNA polymerases isolated from Streptomyces or Micromonospora cells in stationary phase, and prepared as described. To each transcription was added 0.1 units of activity, determined by assaying with calf thymus DNA. Lanes: 1 , Template A + Streptomyces enzyme; 2 , Template A + Micromonospora enzyme; $\mathrm{M}$, molecular mass markers ${ }^{32} \mathrm{P}$ endlabelled HpaII fragments of pBR322 plasmid) with sizes in bp listed; 3, Template B + Streptomyces enzyme; 4, Template B + Micromonospora enzyme. End-to-end transcripts (e) and artificial transcripts (u; see Baum et al., 1989) are indicated. polymerase isolated from stationary cells synthesized in vitro runoff products, utilizing Template A (Fig. $2 b$, lane $1)$, that correspond to the products from the $P 1$ region, from P2, and from Ptk observed previously for this enzyme. The same pattern was observed when Micromonospora RNA polymerase isolated from stationary cells transcribed Template $A$, except that the Ptk transcript was missing (lane 2). Thus in this respect, the in vitro experiments mirrored transcription in vivo, in that 
Streptomyces transformants recognized all of the Micromonospora promoters, and the additional promoter, Ptk. When the shorter Template B was used, the Streptomyces RNA polymerase transcribed from the $\mathrm{P} 1$ promoters and from P2 and Ptk (lane 3), whereas the Micromonospora enzyme again transcribed from all the promoters except for Ptk (lane 4). Thus the in vitro transcription of these Micromonospora templates agreed with the transcription observed in vivo, in terms of start sites and speciesspecific differences in transcription.

\section{Activity of Micromonospora RNA polymerase isolated from vegetative and stationary phase cells}

The $\mathrm{Pl}$ promoters are turned on in vivo in Micromonospora during the stationary phase (Baum et al., 1988). To determine whether a change in RNA polymerase activity might account for this difference in expression, Micromonospora RNA polymerase was prepared from growing cells (vegetative enzyme) and from stationary cells (stationary enzyme), and tested for activity using Templates A and B, shown in Fig. 2(a). The same amount of activity of vegetative or stationary enzymes was added to each reaction, using calf thymus DNA as the standard template.

Fig. 3 shows a comparison of transcription by the vegetative and stationary enzymes. The vegetative enzyme synthesized the $\mathbf{P} 2$ transcripts of Template A, but very little of the $P 1$ transcripts (lane 1 ), whereas the stationary enzyme synthesized less of the P2 transcripts, but considerably more of the P1 transcripts (lane 2). Similarly, when Template B was used, the vegetative enzyme synthesized the P2 transcripts but almost no P1 transcripts (lane 3), whereas the stationary enzyme synthesized less of the P2 transcripts and more of the P1 transcripts (lane 4). The change in the transcription pattern was unambiguous; only the stationary enzyme had the capacity to transcribe the P1 promoters.

\section{Concluding remarks and future directions}

The in vitro experiments showed that the temporal regulation exhibited in Micromonospora in vivo (Baum et al., 1988), was reflected as changed in vitro transcriptional activity during stationary phase. Our favoured hypothesis is that the shift in promoter utilization is due to a new sigma factor(s) present in the stationary RNA polymerase preparation. This possibility is consistent with the presence of alternative sigma factors in species of the actinomycete Streptomyces (Buttner, 1989; Buttner et al., 1988, 1990; Chater et al., 1989; Westpheling \& Browner, 1989; Westpheling et al., 1985), in B. subtilis during sporulation (Losick \& Pero, 1981), and in E. coli

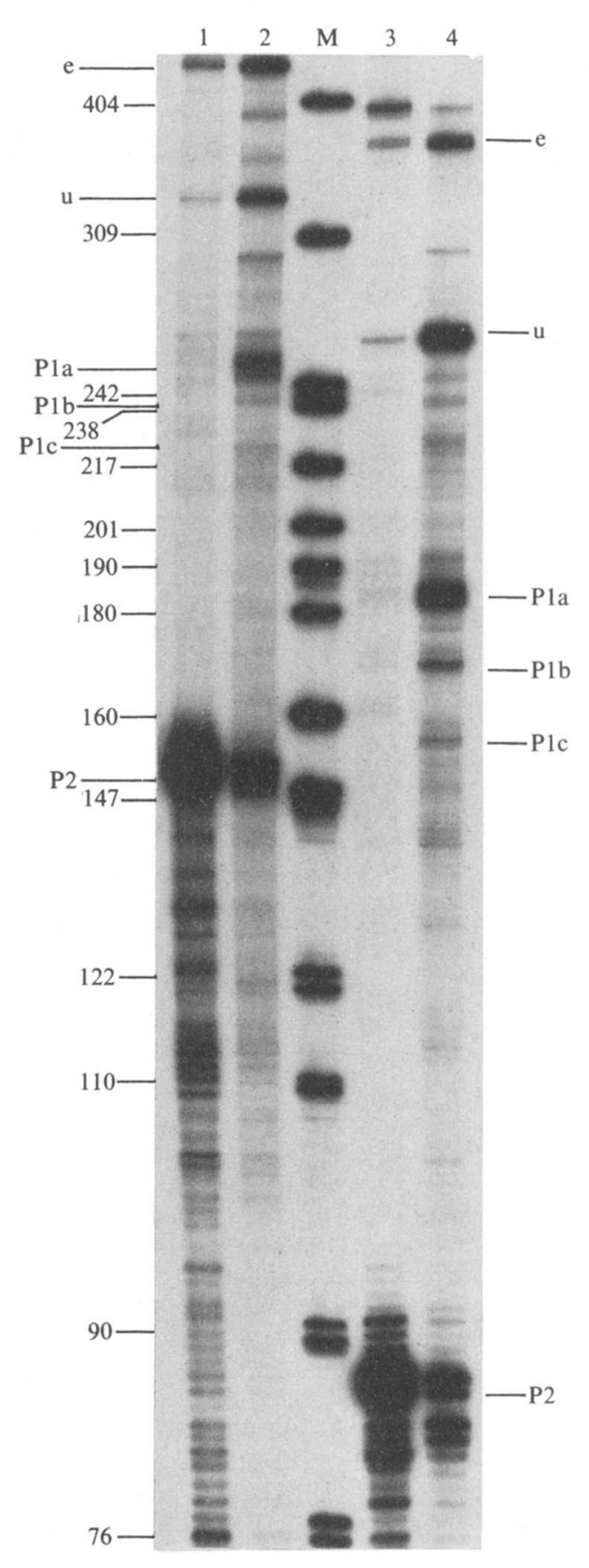

Fig. 3. Temporal changes in RNA polymerase activity isolated from Micromonospora. RNA polymerase was isolated from Micromonospora cells harvested during the growing phase (vegetative enzyme), or from stationary-phase cells (stationary enzyme) as described. These preparations were assayed for runoff transcripts, utilizing Template $A$ and Template B (Fig. 2a). Each reaction contained 0.1 units RNA polymerase, determined by assaying with calf thymus DNA as template. Lanes: 1, Template A + vegetative enzyme; 2 , Template A + stationary enzyme; $M$, molecular mass markers ( ${ }^{32} \mathrm{P}$ end-labelled HpaII fragments of pBR322 plasmid) with sizes in bp listed; 3, Template B + vegetative enzyme; 4 , Template B + stationary enzyme. End-to-end transcripts (e) and artificial transcripts (u; see Baum et al., 1989) are indicated. 
(Gralla, 1991; Grossman et al., 1984). Conclusive evidence awaits a thorough study of the appearance and effect of subunit proteins on promoter specificity of RNA polymerase, as a function of growth stage in Micromonospora.

To our knowledge, this study is the first biochemical evidence to suggest a change in RNA polymerase promoter selection as a function of growth phase in actinomycetes. It is possible that Micromonospora echinospora confers advantages for studies concerning the temporal regulation of gene expression compared to $S$. lividans. Consider the case of differentiation. In most Streptomyces species, the development of aerial and substrate mycelia is distinct, suggesting a complex process and a mixed population of cells. Spores, for example, develop only from aerial mycelia which are distinct from substrate mycelia. Sub-populations of cells undergoing distinct developmental paths may well contain different RNA polymerase forms. If a subpopulation regulated the $P 1$ promoters, so that $P 1$ transcripts were only produced after the growing phase, it might not be detected if the culture also contained another sub-population(s) that expressed the P1 promoters constitutively. In Micromonospora, differentiation may be a simpler and more uniform process. In contrast to $S$. lividans, spores can form in liquid media in Micromonospora, including GER broth, within approximately seven days of incubation (D. M. Rothstein, unpublished results). The ability of Micromonospora to sporulate in liquid culture suggests that the population of cells is differentiating more uniformly. This may account for our observations that a clear change in expression of the P1 promoters occurred during stationary phase in Micromonospora, but not in Streptomyces.

We thank Bill Maiese for his continued support of the Micromonospora project, and Marcia Osburne for critical reading of the manuscript.

\section{References}

Baum, E. Z., Love, S. F. \& Rothstein, D. M. (1988). Temporally regulated tandem promoters in Micromonospora echinospora. Journal of Bacteriology 170, 71-77.

Baum, E. Z., Buttner, M. J., Lin, L.-S. \& Rothstein, D. M. (1989). Transcription from the $\mathrm{P} 1$ promoters of Micromonospora echinospora in the absence of native upstream DNA sequences. Journal of Bacteriology 171, 6503-6510.
BUTTNER, M. J. (1989). RNA polymerase heterogeneity in Streptomyces coelicolor A3(2). Molecular Microbiology 3, 1653-1659.

BUTTNER, M. J. \& BRown, N. L. (1985). RNA polymerase-DNA interactions in Streptomyces: in vitro studies of a $S$. lividans plasmid promoter with $S$. coelicolor RNA polymerase. Journal of Molecular Biology 185, 177-188.

ButtNer, M. J., Fearnley, I. M. \& BibB, M. J. (1987). The agarase gene $(\operatorname{dag} A)$ of Streptomyces coelicolor A3(2): nucleotide sequence and transcriptional analysis. Molecular and General Genetics 209, 101-109.

ButTNER, M. J., SMITH, A. M. \& BiBb, M. J. (1988). At least three different RNA polymerase holoenzymes direct transcription of the agarase gene (dagA) of Streptomyces coelicolor A3(2). Cell 52, 599-607.

Buttner, M. J., Chater, K. F. \& BibB, M. J. (1990). Cloning, disruption, and transcriptional analysis of three RNA polymerase sigma factor genes of Streptomyces coelicolor A3(2). Journal of Bacteriology 172, 3367-3378.

Chater, K. F., Bruton, C. J., Plaskitt, K. A., Buttner, M. J., Mendez, C. \& HelmanN, J. D. (1989). The developmental fate of $S$. coelicolor hyphae depends upon a gene product homologous with the motility $\sigma$ factor of $B$. subtilis. Cell 59, 133-143.

Gralla, J. D. (1991). Transcriptional control - lessons from an E. coli promoter data base. Cell 66, 415-418.

Grossman, A. D., Erickson, J. W. \& Gross, C. A. (1984). The htpR gene product of $E$. coli is a sigma factor for heat-shock promoters. Cell 38, 383-390.

Hopwood, D. A., Bibb, M. J., Chater, K. F., Kieser, T., Bruton, C. J., Kieser, H. M., LydiATE, D. J., SMith, C. P., WARD, J. M. \& SCHREMPF, H. (1985). Genetic Manipulation of Streptomyces: a Laboratory Manual. Norwich, UK: John Innes Foundation.

LAEMMLI, U. K. (1970). Cleavage of structural proteins during the assembly of the head of bacteriophage T4. Nature, London 227 , 680-685.

Lee, M. D., Manning, J. K., Williams, D. R., KuCK, N. A., Testa, R. T. \& Borders, D. B. (1989). Calicheamicins, a novel family of antitumor antibiotics. 3. Isolation, purification and characterization of claicheamicins $\beta_{1}^{\mathrm{Br}}, \gamma_{1}^{\mathrm{Br}}, \alpha_{2}^{\mathrm{I}}, \alpha_{3}^{\mathrm{I}}, \beta_{1}^{\mathrm{I}}, \gamma_{1}^{\mathrm{I}}$, and $\delta_{1}^{\mathrm{I}}$. Journal of Antibiotics 42, 1070-1087.

LOVE, S. F. \& RoTHSTEIN, D. M. (1992). Conditions for protoplasting, regenerating, and transforming the calicheamicin producer, Micromonospora echinospora. Applied and Environmental Microbiology 58, 1376-1378.

Losick, R. \& PERo, J. (1981). Cascades of sigma factors. Cell 29, 582-584.

Maiese, W. M., Lechevalier, M. P., Lechevalier, H. A., Korshalla, J., Kuck, N., Fantini, A., Wildey, M. J., Thomas, J. \& GreEnstein, M. (1989). Calicheamicins, a novel family of antitumor antibiotics: taxonomy, fermentation and biological properties. Journal of Antibiotics 42, 558-563.

Rothstein, D. M. \& Love, S. F. (1991). The isolation of mutants blocked in calicheamicin biosynthesis. Journal of Bacteriology 173, 7716-7718.

WestPheling, J. \& Brawner, M. (1989). Two transcribing activities are involved in expression of the Streptomyces galactose operon. Journal of Bacteriology 171, 1355-1361.

WestPheling, J., RANES, M. \& Losick, R. (1985). RNA polymerase heterogeneity in Streptomyces coelicolor. Nature, London 313, 22-27.

Zein, N. A., Sinha, M., MCGahren, W. J. \& Ellestad, G. A. (1988). Calicheamicin $\lambda^{1}$ : an antitumor antibiotic that cleaves doublestranded DNA site-specifically. Science 240, 1198-1201. 